Document downloaded from:

http://hdl.handle.net/10251/43341

This paper must be cited as:

Payri, R.; Gimeno, J.; Viera, JP.; Plazas Torres, AH. (2013). Needle lift profile influence on the vapor phase penetration for a prototype diesel direct acting piezoelectric injector. Fuel. 113:257-265. doi:10.1016/j.fuel.2013.05.057.

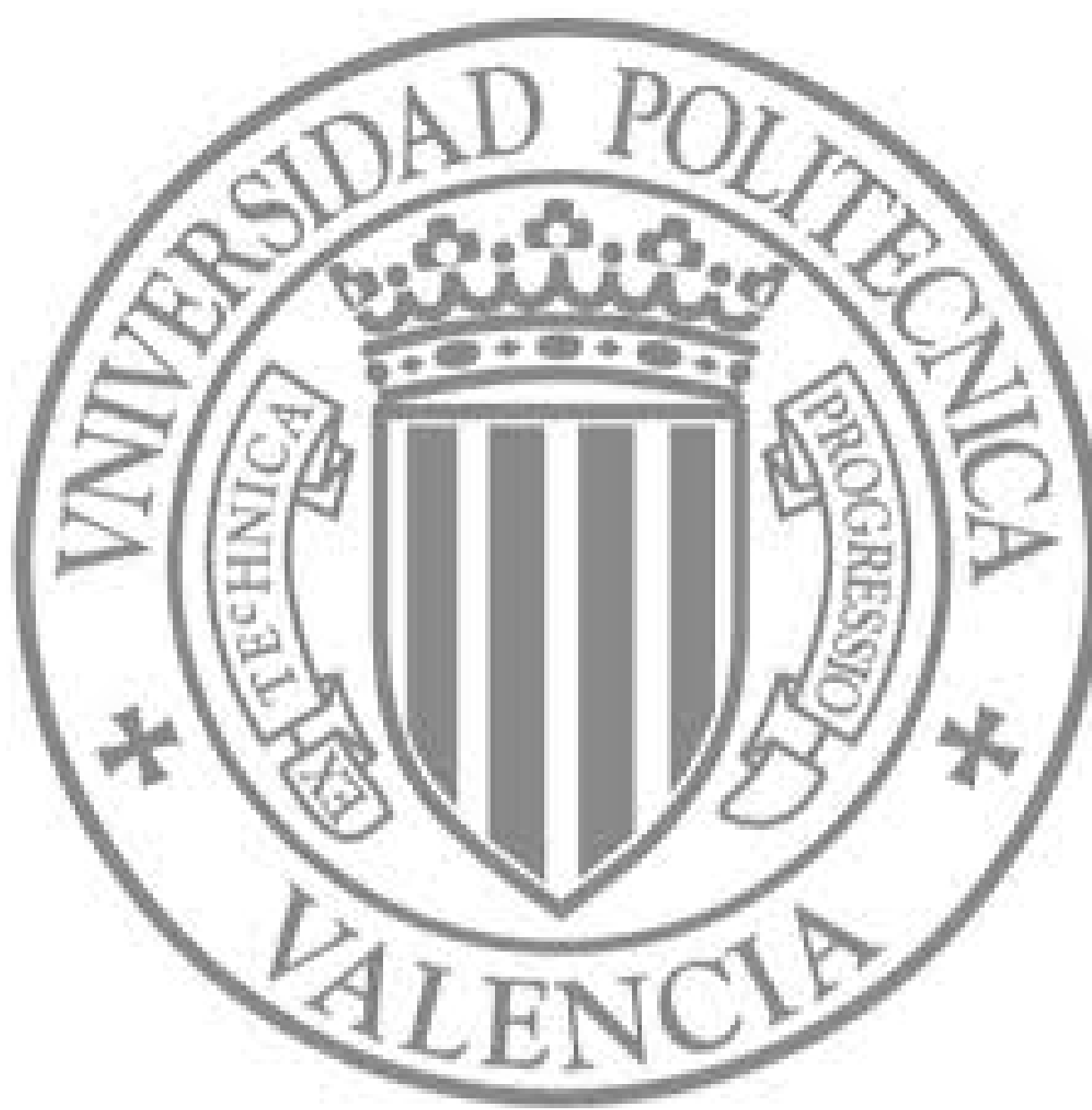

The final publication is available at

http://dx.doi.org/10.1016/j.fuel.2013.05.057

Copyright Elsevier 


\title{
Needle lift profile influence on the vapor phase penetration for a prototype diesel direct acting piezoelectric injector
}

\author{
Raul Payri ${ }^{1}$, Jaime Gimeno ${ }^{1}$ and Juan P. Viera ${ }^{1}$ \\ Alejandro H. Plazas ${ }^{2}$
}

1: CMT-Motores Térmicos - Universitat Politécnica de Valencia, Camino de Vera s/n 46022 Valencia - SPAIN

2: Diesel Engine Systems Group - Propulsion Systems Research Lab, GM R\&D Center, MC: 480106-252, 30500 Mound Rd, Warren, MI 48090-905, USA

\begin{abstract}
In this study, Schlieren visualization tests have been performed for a prototype diesel common rail direct-acting piezoelectric injector, to understand the influence of fuel injection rate shaping on the vapor spray development under evaporative and non-reacting conditions. This state of the art injector presents a particular feature that permits full needle lift control through a parameter referred to as piezo stack charge level, enabling various fuel injection rate typologies. A fast camera and a two pass Schlieren visualization setup have been utilized to record high speed images of the injection event and later analyze, through the vapor phase, the transient evolution of the spray. The tests have been performed employing a novel continuous flow test vessel that provides an accurate control of ambient temperature and pressure up to $1000 \mathrm{~K}$ and $15 \mathrm{MPa}$ respectively. The effect of ambient temperature, injection pressure, needle lift and needle lift profile were studied. Data obtained is correlated to previous liquid length and injection rate measurements of the same injector. Results show, as expected for all cases, that instant vapor penetration rate is closely related to instant injection rate. This is confirmed by
\end{abstract}


the injection pressure test results, along with those obtained for the three different piezo stack charge levels, both affecting the vapor penetration in a similar way. Nevertheless, results obtained for the three different charge levels show that the influence of the charge level and the injection pressure differ in the very beginning of the injection event, where the spray development is largely determined by needle lift and not injection pressure. Ambient temperature alone seems not to have and important effect on vapor penetration. Finally, the effects of the needle lift profile in the instant injection rate and vapor penetration are presented, confirming the strong relation between these three parameters, and confirming also that the needle lift plays a determinant role in the spray development, especially at the early stages of the injection process. Both boot and ramp shaped injections proved the ability to strongly influence the vapor penetration rate. In comparison to the square shaped injection, the effect of the ramp shaped injection delays the vapor penetration right from the start of injection while the effect of the boot shaped injection takes considerably longer to become noticeable. From the results, the needle lift control feature has proven to be a very versatile tool for engine designers to control the injection process as desired, opening a new path with a plenty of room for improvement.

Keywords: Diesel, lift profile, injection rate, spray momentum, vapor penetration.

(*) Corresponding author: Dr. Raúl Payri, rpayri@mot.upv.es 


\section{INTRODUCTION}

Internal combustion engines have played a very important role in the world since their introduction around a century ago. They opened infinite new possibilities for people and shaped the world that we now know. However, recent concerns regarding the environmental impact of gaseous and particulate emissions that engines produce, along with the ever more demanding fuel consumption standards, have pushed the industry into the research of new technologies and strategies, in between which, the injection process takes a determinant part [1][2][3].

Current development of piezo-actuated injectors is the direct acting system, where a piezoelectric actuator has direct control on the injector needle lift allowing for a fast and precise control of the fuel flow through the injector nozzle. This feature is unique and important, not only because it introduces full control of the needle lift for the first time, but also because it enables the ability to control the injection event in both the stationary and transient stages. Likewise, the ability to control the actual needle lift from the beginning of the injection implies faster response and better control of the injection event timing.

Several studies have been performed in last decades in order to predict the spray behavior as well as to aid the development of numerical models, either based on physical assumptions or simply interpolating experimental data $[3][4][5][6][7]$. Although there has been research works performed to analyze the injection event using conventional servo-hydraulic injectors, only a few are discussing the effect of the partial needle lift on the injection process [8][9][10]. In order to develop a better understanding of the effect of partial needle lift on the atomization and evaporative performance of the injector, this research has carried out an experimental study to measure vapor phase penetration of the fuel spray produced by a direct acting injector, using a controlled 2-pass Schlieren setup.

The study has been performed in a high temperature and high pressure test rig, capable of reaching $15 \mathrm{MPa}$ ambient pressure and $1000 \mathrm{~K}$ ambient temperature. The large optical accesses and the wide test 
section permit studying the spray with high accuracy in a homogeneous temperature and nearly quiescent environment. Different parameters have been varied: ambient temperature, injection pressure, needle lift (piezo stack charge level) and needle lift profile.

The research carried out, shows that the needle lift control turns out to be largely determinant in the vapor spray development process, suggesting that all the particularities of the new technology offer the engine design engineers a wide variety of injection strategies to think of. Therefore, a deep understanding of the injector performance in all the range of its operating possibilities has to be reached.

This article is structured in five parts: first the present introduction, next the experimental setup with an explanation of the test rig and the optical hardware utilized, later the main results and analysis are exposed, next an empirical correlation that predicts the vapor penetration as a function of the spray momentum flux is presented to finalize with the main conclusions of the paper.

\section{EXPERIMENTAL METHODOLOGY AND SETUP}

\subsection{THE FUEL INJECTION SYSTEM}

A common-rail injection system was used. It is constituted by a high pressure pump and a conventional rail with an electronic pressure regulator, which allows fuel injections under high (up to $200 \mathrm{MPa}$ ) and constant rail pressure [2][3][11]. The injector temperature was kept close to $343 \mathrm{~K}$ using a special injector holder designed to have coolant flowing at a controlled temperature in direct contact with the injector body. The study was performed using commercial Diesel fuel with a density of 812 $\mathrm{kg} / \mathrm{m}^{3}\left(\right.$ at $70^{\circ}$ ) and kinematic viscosity of $1.910^{-6} \mathrm{~mm}^{2} / \mathrm{s}\left(\right.$ at $70^{\circ}$ ). The fuel was injected using with a 7orifice nozzle (Outlet diameter $\mathrm{D}_{0}=156 \mu \mathrm{m}$, k-factor $=1.5[8]$ ) which permits full control of the needle lift position through the voltage profiles applied to the piezo stack [9]. The complete injection system is electronically controlled by the ECU and all the settings are introduced digitally. 


\subsection{THE HIGH PRESSURE AND HIGH TEMPERATURE TEST RIG}

The tests have been performed in a high temperature and high pressure test vessel where the in-cylinder thermodynamic conditions of a Diesel engine at the time of injection can be reproduced. The rig allows a maximum ambient temperature of $1000 \mathrm{~K}$ and maximum pressure of $15 \mathrm{MPa}$ in the test chamber, which is illustrated in Figure 1. As can be seen from the figure, the test section has three large optical accesses (128 $\mathrm{mm}$ in diameter) placed orthogonally in order to have complete optical access to the injection event. The complete test rig functioning and principles are precisely described in [10].

There are several facilities in the world capable of operating at similar conditions $[12][13][14][15]$. Still, this particular test rig is capable of obtaining nearly quiescent, and steady thermodynamic conditions for very long periods of time. This design allows a better (and easier) control and replication of real engine-like test conditions [13]

Engines with optical access are commonly used for similar purposes [16][17][18][19][20][21], but although they replicate more realistic conditions, they also introduce a lot of factors that could be undesired for the scope of certain studies, where a more controlled environment would be better suited. In these engines fuel distribution is affected by swirl and turbulent in-cylinder flow, and visualization is usually limited due to the geometric and space limitations of an operating engine. Alternatively, measurements under steady ambient conditions are more convenient to study and isolate spray subprocesses. The steadier thermodynamic conditions provide a high test repetition rate and quality, improving the global accuracy of the data acquired. In this study, the vessel has been filled with nitrogen to guarantee the evaporative but non reacting conditions sought.

\subsection{OPTICAL SETUP}

The Schlieren technique is based on directing a beam of parallel rays of light across a region of interest, collecting this beam and filtering or discarding some of the deflected light, to finally form a shadowgraph in which different pixel intensities represent different refractive indexes in the region of interest [21]. 
A scheme of the optical setup is represented in Figure 2. Being the injector nozzle a multi-hole nozzle, frontal visualization was necessary, which suggests the use of a two pass setup with a mirror just beneath the injector nozzle. This scheme shows the path of the light throughout the whole setup including the high pressure and high temperature vessel. The yellow and orange translucent beams represent light paths before and after reaching the mirror, respectively. The beam splitter is employed to separate light before and after it has been through the test area. Both the single point light source and the Fourier filtering diaphragm are purposely located at the focal length of Lens B.

The filtering or discarding device utilized in this project consists of an adjustable diameter diaphragm which lets light past its center hole while blocking the rest. This would fall in the category of a circular type cut-off device, which performs symmetrically if everything is properly aligned. The diameter of the center hole is adjustable so that it is possible to decide how much light is desired to be allowed into the camera. This adjustment is what actually controls the system's sensibility, by letting the user decide how deflected is the light that is being blocked.

Lens A was introduced to better focus the light source into a smaller and more intensified single point, which is important as this is closely related to the quality of the collimating. The utilization of just one lens for collimating and collecting (Lens B) was decided in order to reduce the length of the test area to the minimum possible, thus maximizing the collection angle.

Table 1 presents the details of the optical setup prepared and the devices utilized in it. The pixel/mm ratio obtained, along with the image size in pixels produce a considerably large image; a field of view of approximately $114 \mathrm{~mm} \times 114 \mathrm{~mm}$. For the camera utilized, the image size obtained is due to a slight sacrifice in acquisition speed, which could be higher along with a smaller image. Nevertheless, the speed was considered to be enough for the vapor penetration rates involved and the field of view obtained permits the visualization of vapor up to almost the maximum permissible by the window diameter which is $128 \mathrm{~mm}$. 


\subsection{IMAGE PROCESSING}

The image processing is one of the most important parts of any visualization data analysis [4][22]. Images were processed with purpose developed software. During processing, each image is first divided into 7 sectors, each for one outlet orifice and thus one spray. Each spray is processed separately, by masking the image in order to get only the spray of interest. The algorithm details are described in [10], although [22] and Figure 3 illustrate the principle clearly. The image is inverted in order to have the spray as the high luminosity area and the threshold is calculated as the $0.5 \%$ of that image's dynamic range [10][23]. Then, small areas that result of background noise are ruled out and finally the spray contour is "cleaned" free of small noise fluctuations through a pixel connectivity evaluation. This last step could be seen as a contour smoothing, as Figure 3 illustrates. Hence, the characteristics of the spray shape are obtained by analyzing its contour:

- The vapor spray penetration is calculated detecting the point on the contour that is the furthest from the outlet orifice.

- The spreading angle is calculated as the angle included between the two lines that fit the points on the spray contour in a specific region, and are forced to go through the outlet orifice. The region of the spray contour that is fitted goes from a $25 \%$ to $60 \%$ of the vapor spray penetration. The part close to the nozzle outlet is excluded because no Schlieren effect could be visualized there due to the injector and the isolator ceramic being non-reflective.

\subsection{SETUP LIMITATIONS}

The mirror is essential to the proper performance of the optical setup. The mirror had four nonreflective areas in its surface: three holes for bolts that hold the mirror against the injector holder and a center hole to fit the injector nozzle. The center hole diameter is larger than the nozzle body outer diameter, in order to fit a cylindrical ceramic isolator that helps isolating the nozzle from the high temperatures. These non-reflective parts of the mirror plane interrupt visualization, since light not reflected is never collected at the sensor of the camera. This meant that the clear visualization of three of 
the seven sprays was disturbed by these bolts, as the sprays traveled across the bolt's head diameter. This also means that since the nozzle is non reflective either, spray contours could only be detected after a few millimeters of penetration had been reached. Hence, the three sprays that traveled through the bolts were excluded from the final data averaging, to ensure that the averaging is done from "clean" data. Therefore, results presented regard only the average of four of the seven sprays.

\subsection{DATA AVERAGING}

In order to obtain the mean value of the vapor spray penetration and to filter the experimental noise, a moving average technique has been implemented. In each single experiment, a data point $y_{i}$ is obtained at an instant $t_{i}$, which corresponds to the time elapsed after the start of the injection. The average value $y_{i}$ at the instant $t_{i}$ is obtained following this procedure:

- The data set falling in the interval $t_{i} \pm \Delta t / 2$ is considered. An optimal time window $\Delta t$ of $150 \mu \mathrm{s}$ has been chosen for the current test.

- Over the data set selected, a linear fit is applied and the value of $y_{i}$ is obtained substituting $t_{i}$ in the equation obtained in the linear fit.

- This algorithm is repeated moving $t_{i}$ along the time line with $15 \mu$ s time step; then the averaged curve is obtained.

\subsection{IMAGE SYNCHRONIZATION}

Being a two pass system, the first few millimeters of spray penetration were not possible to catch because the injector nozzle and its ceramic isolator are not reflective. In addition, the triggering mode of a fast camera causes uncertainty in the start of the recording.

It is known that the liquid and vapor penetration curves are not distinguishable at the first part of the injection process [18][20][24], so the best approach was to perform a time-alignment of the vapor penetration curves with the previously obtained liquid penetration curves [9] so that they coincide with each other in the early stages of the injection process. The SOI for liquid penetration has been 
extrapolated properly in [9], due to a much higher sampling rate along with the visualization setup permitting the visualization of the spray from the very first few millimeters.

\subsection{EXPERIMENTAL TEST PROGRAM}

The test program has been designed to understand the effect of partial needle lift in the vapor penetration during both the transient and the steady part of the injection. Tests have been performed varying the ambient temperature, injection pressure and needle lift, and each test point was repeated 15 times. The conditions tested are described in the test plan summarized in Table 2. In particular, needle lift tests were separated into three different cases:

- Square shaped injection. The first case was the square shaped injection, where the needle lift profile emulated a square shaped profile similar to those found in conventional injectors. In this case, three different piezo stack charge levels were tested, considering that the charge level controls the needle lift, so the lower the charge level the lower the maximum needle lift.

- Boot shaped injection. The second case was the boot shaped injection, which consists of a two stage squared shaped injection where the needle lift is controlled in such way that each stage has a particular mass flow rate. In the first stage, the needle is rapidly lifted to a certain value which yields a stabilized injection mass flow rate of $40 \%$ of that of the square shaped injection in the high charge level case. After this first stage, the needle lifts rapidly to the second lift value which yields the same injection rate as the square shaped injection in the high charge level case.

- Ramp shaped injection. The lift profile in this case follows a ramp, that lifts the needle gradually, and not rapidly like in the square case, to the maximum lifts which yields, again, the same injection rate as the squared shaped injection in the high charge level case. 


\section{RESULTS AND DISCUSSION}

In this section, vapor penetration results are presented. Each vapor penetration curve (continuous lines in all penetration figures) has been plotted over the corresponding liquid penetration curve (dashed lines in all penetration figures) obtained in [10]. The injector's instant mass flow rates were previously measured in [8] for each condition in the test plan and are also represented in the following figures to better understand the behavior of the injector.

\subsection{INFLUENCE OF THE AMBIENT TEMPERATURE}

Two ambient temperatures were tested, and the effects on vapor penetration were studied. As expected, ambient temperature does not affect the vapor penetration in any significant way. The same cannot be said about the liquid penetration which clearly depends on ambient temperature, being the later a determinant factor in the vaporizing process. But once the fuel is vaporized the spray development is not affected by temperature but by other more determinant factors, like spray momentum or ambient density, for instance. It is important to remember that the ambient pressure was kept constant at 50 bar, so the temperature difference alone caused a density variation of less than $8 \%$, which is not significant in terms of penetration.

\subsection{INFLUENCE OF THE INJECTION PRESSURE}

As previously exposed in Table 2, two injection pressures were tested, and the effects over vapor penetration were studied. Figure 4 illustrates the influence of the injection pressure. As expected, an increase in injection pressure produces an increase in vapor penetration rates. These results agree with those previously obtained for the momentum flux and mass flow rates of this same injector by the authors in [8][9] and the relation between mass flow rate, momentum flux and outlet velocity [25][26]. Even so, the injection pressure effect is noticeable only after the spray has penetrated to a certain extent, since at the beginning of the injection the spray development is more dependent on the actual needle lift than on the injection pressure, being the former the determinant factor at this stage, as it can be seen in the next section. 


\subsection{INFLUENCE OF THE PIEZO STACK CHARGE LEVEL IN THE SQUARE SHAPED LIFT PROFILE}

Three different piezo stack charge levels were tested for the square shaped lift profile, and the effects over vapor penetration were studied. Figure 5 illustrates the influence of the piezo stack charge level. In this case, only the low temperature case is presented, although the other case shows similar results. Furthermore, it has been seen that temperature does not play a key part in the vapor spray development. The influence of the piezo stack charge level is clearly appreciable in Figure 5, and the effect is similar to that of the injection pressure: increasing the piezo stack charge level increases the injection rate thus increasing the vapor penetration rate. This, again, agrees to what the authors found in [9][8], where the momentum flux of the injection spray increased with the piezo stack charge level. This result is expected since the partial needle lift causes a pressure drop in the nozzle entry, and this drop is reduced as the needle lift is increased.

Nevertheless, there is a slight difference between the injection pressure effect and the piezo stack charge level effect, and it is right after the start of injection. As stated before, at the beginning of the injection process it seems that, with this injector, the spray development is more dependent on the actual needle lift than on injection pressure, because the needle is not hydraulically lifted as it is in a conventional injector. This means that the piezo stack charge effect over spray development is noticeable from the start of injection, unlike the injection pressure effect. This behavior was noticeable already when the first hydraulic characteristic measurements were performed in [8] at the beginning of the study of this injector, and it also appeared in the liquid penetration curves shown in [10], measured later. The results presented, along with those obtained in these two previous studies, clearly confirm that this is a consistent behavior and that the needle lift plays a key role in both the transient and the steady stages of the injection process.

The needle lift results presented regard three different needle lift values, but always under a square shaped lift profile similar to that of conventional injectors. Thus, they lead the way to think of the effects 
a particular lift profile would have in the vapor penetration values and rates. The study of the needle lift profiling is covered in the next two cases presented.

\subsection{INFLUENCE OF THE BOOT SHAPED LIFT PROFILE}

This section presents the case of the boot shaped profile and its effects on vapor penetration, as illustrated in Figure 6. The equivalent (in rail pressure and ambient temperature) high charge level square shaped case is shown in black as a reference for comparison.

In this case, only the low temperature case is presented, although the other case shows similar results. In the first part of the injection, the vapor penetration curve clearly shows how the reduction in the injection rate reduces also the penetration rate. On the same lines, it can be seen that, when both injection rates converge to the same value, in the second stage of the boot shaped profile, the penetration curves become parallel, indicating a similar penetration rate. However, this cannot be observed in the high pressure case, in which both the square and boot shaped sprays reach the visualization limit before getting to the equal injection rate part of the injection process.

From these results, it could be said that the boot shaped profile is able to delay or shift the vapor penetration in time, but doing this while maintaining the same SOI timing, which surely proves to be a very versatile feature for the engine designer to control the injection event development as desired.

\subsection{INFLUENCE OF THE RAMP SHAPED LIFT PROFILE}

This section presents the case of the ramp shaped profile and its effects over vapor penetration, as illustrated in Figure 7. The equivalent (in rail pressure and ambient temperature) high charge level square shaped case is shown in black as a reference for comparison.

Again, only the low temperature case is presented. It can be observed in Figure 7 that the ramp shaped injection reaches its stable injection rate flow considerably slower than the square shaped injection. This has an effect somewhat similar to that of the boot shaped injection, delaying the vapor penetration or off-setting it in the time domain. However, although both effects seem similar (both shifting the penetration curve in the time domain but maintaining the same SOI timing as the square 
shaped case) they still differ slightly: the delay on the ramp shaped injection occurs right from the start of injection while it takes longer for the boot shaped injection effect to be noticeable. This difference may seem small, but can be a key factor when determining how to profile the injection when trying to control the injection event to achieve a given target.

This early delaying effect was already observed in the piezo stack charge level tests (for the square shaped profile), where unlike in the injection pressure tests, the vapor penetration was affected from the beginning of the injection process. The ramp shaped profile effect could be seen as an extension of this, where the penetration rate is influenced even more, from the start of injection. This, once more, confirms the importance of the injector needle lift and its powerful influence on the spray development.

After this study, it is clear that the needle lift control is a very strong tool to manage the vapor spray development, producing effects that were not possible to get with conventional injector control parameters. Nonetheless, in this research work only three profiles were tested but there exist infinite different variations to think of, each of them would have different outcomes in the liquid and vapor spray developments. In addition, it is important to mark that the results obtained in this study along with those obtained in previous works presented in [9] and [10], open room for a lot of different questions that could lead to further studies regarding the influences that this technology could have, not only on the inert injection spray, but also in the reactive spray and the complete engine performance.

\subsection{CORRELATION FOR THE VAPOR PHASE PENETRATION}

Data gathered in this study allowed the fitting of an empirical correlation that would permit future predictions of the vapor penetration for this injector. There have been various approaches for penetration correlations in the literature, some of them taking into account the injection pressure, while others rely on the momentum flux measurements of the spray. In this case, the base correlation presented in [27] was adopted. However, the power coefficients were left as additional fitting parameters for the model to better reproduce the experimental data, as shown in the equation (1): 


$$
S=k \rho_{a}^{1 / 4} M^{a} t^{b} \tan ^{c}(\theta / 2)
$$

Where $S$ represents vapor spray tip penetration, $k$ is just a proportioning constant, $\rho_{a}$ is the ambient density, $M$ is the momentum flux, $t$ is the time for which the penetration $S$ is being predicted and $\theta$ is the spray spreading angle. The previous equation is then fitted to the experimental data through a nonlinear regression, and all the constants are adjusted for the best fit using the Levenberg-Marquardt algorithm [28] for nonlinear least squares to compute non-robust fits.

The experimental data utilized for the fit, consist of the combination of the vapor phase visualization results, with the hydraulic measurements. For each given condition of the test plan, there is a time-wise penetration vector with the corresponding time vector. Ambient density is fixed by the ambient temperature and pressure for that test condition. For those same conditions, the momentum flux and spreading angle are the time-average calculated in the stabilized region of the momentum flux curve [8] and the spreading angle time response obtained in this study from the Schlieren images. This implies that the model "sees" the influences of injection pressure and needle lift as consequences of the corresponding momentum flux and spreading angle introduced. This also implies that the correlation does not "see" the influence of ambient density, which was kept out of the scope of this study and thus its coefficient was kept constant.

It is important to highlight that the experimental data was cut to a minimum penetration of $20 \mathrm{~mm}$, to ensure that the model fits the data correctly the region of interest which is after the injection has stabilized. On the upper limit, it can be seen in Figure 9 that data is available up to the visualization limit which is around the half of the width of the image $(114 \mathrm{~mm})$. Table 3 presents the results obtained for coefficients through the nonlinear regression. Looking at the results the exponents found for spray momentum (0.21) and for the time exponent (0.6) are in accordance with exponents found in theoretical studies [27]. 
Measuring momentum flux is considerably easier than visualizing the vapor phase spray development, especially for a multi hole nozzle, so the momentum flux approach surely presents a great advantage. Utilizing momentum flux in the correlation also has the advantage of including in the regression the effects of the injection pressure. These are the two main reasons why the correlation is of great value, since it demonstrates that injection pressure and partial needle lift can be modeled simply by their influence on spray momentum. This had already been proved for the injection pressure [27], but this study also validates for the first time the approach for partial needle lifts.

Figure 8 shows the modeled data plotted over the corresponding experimental data. This demonstrates how the effects of the needle lift and injection pressure can be reproduced by the model, with a correlation coefficient $\mathrm{R}^{2}=0.984$, by implementing the momentum flux approach.

Figure 9 depicts the experimental data vs. the predicted data. A linear relation between the two can clearly be observed which suggests, once more, good agreement between the model and the results obtained.

\section{SUMMARY AND CONCLUSIONS}

The objective of this study was to understand the influence of a certain group of variables in the vapor spray development. The effects of ambient temperature, injection pressure, needle lift and needle lift profile were studied in a novel, constant flow high pressure and high temperature test rig. The facility emulates in-chamber conditions at the time of injection by means of pressurized and heated gas, to a maximum pressure and temperature of 150 bar and $1000 \mathrm{~K}$ respectively. The main advantage of this constant flow facility is that it can maintain test conditions for a considerable time, so boundary conditions at the time of injection can be precisely controlled.

First, results show that the ambient temperature alone seems not to have an important effect on vapor penetration. Therefore, these results were not presented as they were not considered relevant, although it can be indirectly appreciated in Figure 4. Results also show that the needle lift and injection 
pressure affect the vapor penetration and spreading angle in a similar way. An increase in either of the two will cause an increase in the vapor penetration rate. This was expected because of the results the authors presented in [8][9]. On the other hand, the beginning of the injection process seems to be more dependent on the actual needle lift than on the injection pressure, so the effect of the charge level can be noticed right after the SOI while the injection pressure needs a certain spray development to show its effect. This also suggests that needle lift profiling would delay the vapor penetration curve, as was confirmed later by the results, and depending on the actual needle lift profile different outcomes can be obtained. In comparison to the square shaped injection, the effect of the ramp shaped injection delays the vapor penetration from the start of injection, while the effect of the boot shaped injection takes considerably longer to become noticeable. The needle lift profile tests proved that the ramp and boot profiles are two different approaches that a particular engineer could follow to control the vapor penetration at will.

Finally, an empirical correlation for the vapor phase spray penetration was obtained through a nonlinear regression of the experimental data. Predicted data shows good agreement with the experimental results, and a clear linear correlation can be observed between the two.

The spray penetration rate is a key factor in the combustion process, since it has a great influence in the air utilization and mixing process [24]. With these results it is possible to say that engine design engineers could now control the vapor penetration rate not only with the injection pressures but also with the needle lift and needle lift profile. This is a unique and novel feature of this injector and these results, along with those obtained in [8][10], open room for different questions that could lead to further studies regarding the influences that this technology could have over, not only the inert injection spray, but also the reactive spray and the complete engine performance. 


\section{ACKNOWLEDGMENTS}

The authors would like to thank general motors company for their financial support and its cooperation during the project and José Enrique del Rey* and Michele Bardi* for their collaboration in the experimental measurements and setup.

(*) From CMT-Motores Térmicos. Universitat Politecnica de Valencia. 


\section{REFERENCES}

[1] Soid SN, Zainal ZA, Spray and combustion characterization for internal combustion engines using optical measuring techniques - A review, ENERGY 2011; 36 (2): 724-741.

[2] Payri R, Salvador FJ, Gimeno J, De la Morena J, Influence of injector technology on injection and combustion development - Part 1: Hydraulic characterization, Appl. Energy 2011; 88 (4): 10681074.

[3] Payri R, Salvador FJ, Gimeno J, De la Morena J, Influence of injector technology on injection and combustion development - Part 2: Combustion analysis, Appl. Energy 2011; 88 (4): 1130-1139.

[4] Siebers DL, Liquid-Phase Fuel Penetration in Diesel Sprays, SAE Paper 980809; 1998.

[5] Myong K, Arai M, Suzuki H, Senda J, Fujimoto H., Vaporization Characteristics and LiquidPhase Penetration for Multi-Component Fuels, SAE Paper 2004-01-0529; 2004.

[6] Ramos J, Internal combustion engine modeling, Hemisphere publishing corporation, ISBN 089116-157-0; 1989.

[7] Som S, Ramirez AI, Longman DE, Aggarwal SK, Effect of nozzle orifice geometry on spray, combustion, and emission characteristics under diesel engine conditions, FUEL 2011; 90 (3): 1267-1276.

[8] Payri R, Gimeno J, Venegas O, Plazas AH, Effect of Partial Needle Lift on the Nozzle Flow in Diesel Fuel Injectors, SAE Paper 2011-01-1827; 2011.

[9] Payri R, Gimeno J, Venegas O, Plazas-Torres AH, Experimental and computational study of the influence of partial needle lift on nozzle flow in diesel fuel injectors, Atomization and Sprays 2012; 22(8): 687-714.

[10] Payri R, Gimeno J, Bardi M, Plazas AH, Effect of injection rate shaping over diesel spray development in non reacting evaporative conditions, ASME ICES2012-81206; 2012. 
[11] Som S, Aggarwal SK, El-Hannouny EM, Longman DE, Investigation of Nozzle Flow and Cavitation Characteristics in a Diesel Injector, Journal of Engineering for Gas Turbines and Power 2010; 132 (4): 042802.

[12] Baert R, Frijters P, Somers B, Luijten C, Design and operation of a high pressure, high temperature cell for HD diesel spray diagnostics: guidelines and results, SAE Paper 2009-01-0649; 2009.

[13] Meijer M, Somers B., Johnson J, Naber J, Lee SY, Malbec LM, Bruneaux G, Pickett LM, Bardi, M, Payri R, Bazyn T, Engine Combustion Network (ECN): Characterization and comparison of boundary conditions for different combustion vessels, Atomization and Sprays 2012; 22(9): 777806.

[14] Pickett L, Genzale CL, Manin J, Malbec LM, Hermant L, Measurement Uncertainty of Liquid Penetration in Evaporating Diesel Sprays, ILASS2011-111; 2011.

[15] Parrish SE, Zink R, Development and application of an imaging system to evaluate liquid and vapor envelopes of sprays from a multi-hole gasoline fuel injector operating under engine-like conditions, ILASS2011-170; 2011.

[16] Bermúdez V, García JM, Juliá E, Martínez S, Engine with optically accessible cylinder head: A research tool for injection and combustion processes, SAE Paper. 2003-01-1110; 2003.

[17] Krämer H, Einecke S, Schulz C, Sick V, Nattrass SR, Kitching JS, Simultaneous mapping of the distribution of different fuel volatility classes using tracer-LIF tomography in an IC engine. SAE Paper $982467 ; 1998$.

[18] Fisher BT, Mueller CJ, Liquid penetration length of heptamethylnonane and trimethylpentane under unsteady in-cylinder conditions, Fuel, 2010; 89: 2673-2696.

[19] Mueller CJ, Martin GC, Briggs TE, Duffy KP, An experimental investigation of incylinder processes under dual-injection conditions in a DI diesel engine, SAE Paper 2004-01-1843; 2004. 
[20] Pastor JV, Payri R, García-Oliver JM, Briceño FJ, Analysis of transient liquid and vapor phase penetration for diesel sprays under variable injection conditions, Atomization and Sprays 2011; 21(6): 503-520.

[21] Payri R, Salvador FJ, Garcia A, Gil A, Combination of Visualization Techniques for the Analysis of Evaporating Diesel Sprays, Energy \& Fuels 2012; 26(9): 5481-5490.

[22] Macian V, Payri R, Garcia A, Bardi M, Experimental Evaluation of the Best Approach for Diesel Spray Images Segmentation, Experimental Techniques 2012; 36(6): 26-34.

[23] Siebers DL, Scaling liquid-phase fuel penetration in Diesel sprays based on mixing-limited vaporization, SAE Paper 1999-01-0528; 1999.

[24] Kook S, Pickett LM, Liquid length and vapor penetration of conventional, Fischer-Tropsch, coalderived, and surrogate fuel sprays at high-temperature and high-pressure ambient conditions. Fuel 2012; 93: 539-548 (2012).

[25] Payri R, García JM, Salvador FJ, Gimeno J, Using spray momentum flux measurements to understand the influence of Diesel nozzle geometry on spray characteristics, Fuel 2005; 84: 551561.

[26] Payri R, Salvador FJ, Gimeno J, Zapata LD, Diesel nozzle geometry influence on spray liquidphase fuel penetration in evaporative conditions, Fuel 2008; 87: 1165-1176.

[27] Desantes JM, Payri R, Salvador FJ, Gil A, Development and validation of a theoretical model for diesel spray penetration, Fuel 2006; 85: 910-917.

[28] Seber GAF, Wild C J, Nonlinear Regression, Hoboken, NJ: Wiley-Interscience, 2003, doi: $10.1002 / 0471725315$. 
Appendix A equations

Eq. (A.1)

$$
S=k \rho_{a}^{1 / 4} M^{a} t^{b} \tan ^{c}(\theta / 2)
$$

FUEL; Volume: 113; Pages: 257-265; DOI: 10.1016/j.fuel.2013.05.057; NOV 2013 
Appendix B Figure captions

Fig. (B.1) Figure 1 High temperature and high pressure visualization test rig.

Fig. (B.2) Figure 2 Scheme representing the optical setup.

Fig. (B.3) Figure 3 Image sequence example. Top left: original image. Top center: inverted image. Top right: image after masking and threshold binarization. Bottom left: image after small area filtering. Bottom center: image after pixel conectivity evaluation. Bottom right: final contour detected and plotted over original image.

Fig. (B.4) Figure 4 Influence of the injection pressure in the vapor penetration. a) Tamb= $870 \mathrm{~K}, \mathrm{ch} \%=$ med. $\quad$ b) $\mathrm{Tamb}=950 \mathrm{~K}, \mathrm{ch} \%=$ med.

Fig. (B.5) Figure 5 Influence of the piezo stack charge level in the vapor penetration. a) $\mathrm{Tamb}=870 \mathrm{~K}$, Pinj $=600$ bar. b) Tamb $=870 \mathrm{~K}$, Pinj $=1500$ bar.

Fig. (B.6) Figure 6 Influence of the boot shaped lift profile in the vapor penetration. a) Tamb $=870 \mathrm{~K}$, Pinj $=600$ bar. b) Tamb $=870 \mathrm{~K}$, Pinj $=1500$ bar.

Fig. (B.7) Figure 7 Influence of the ramp shaped lift profile in the vapor penetration. a) Tamb $=870 \mathrm{~K}$, Pinj $=600$ bar. b) Tamb $=870 \mathrm{~K}$, Pinj $=1500$ bar.

Fig. (B.8) Figure 8 Vapor spray tip penetration for the three charge levels tested, experimental data vs. fitted model for a) Tamb $=870 \mathrm{~K}$, Pinj $=600$ bar and $b$ ) Tamb $=870 \mathrm{~K}$, Pinj $=1500$ bar.

Fig. (B.9) Figure 9 Experimental data vs. predicted data. 
Appendix C Table captions

Tab. (C.1)

Table 1 Details of the optical setup and devices.

Tab. (C.2) Table 2 Experimental test program.

Tab. (C.3) Table 3 Fitted experimental correlation coefficients

FUEL; Volume: 113; Pages: 257-265; DOI: 10.1016/j.fuel.2013.05.057; NOV 2013 
Table 1 Details of the optical setup and devices.

\begin{tabular}{ll}
\hline Acquisition camera & Phantom V12 CMOS high-speed camera \\
Acquisition frame rate [frames/second] & 14834 \\
Acquisition time step [ $\mu \mathrm{s}]$ & 67 \\
Camera lens & Nikkor 50mm 1:1.8 \\
Light source & STORZ Xenon NoVA 300 \\
Lens A & Nikkor 50mm 1:1.8 \\
Lens B & TSI $\mathrm{f}=450 \mathrm{~mm}$ \\
Beam splitter & Edmund Optics 50:50 \\
Mirror & Custom made stainless steel polished mirror \\
Image size [pixels] & $608 \times 608$ \\
Image pixel/mm ratio [pixel/mm] & 5.33 \\
Image size [mm] & $114 \times 114$ \\
Number of repetitions per test point & 15 \\
\hline
\end{tabular}

Table 2 Experimental test program.

\begin{tabular}{llc}
\hline Parameter & Value - type & Units \\
\hline Fuel & Commercial & - \\
Orifice diameter & Diesel & $\mathrm{mm}$ \\
k-factor & 0.152 & - \\
Energizing time & 1.5 & $\mu \mathrm{s}$ \\
Injector coolant temperature & 3200 & $\mathrm{~K}$ \\
Ambient gas pressure & 343 & $\mathrm{bar}$ \\
Ambient gas temperature & 50 & $\mathrm{~K}$ \\
Injection pressure & $870-950$ & $\mathrm{bar}$ \\
Needle lift profiles & $600-1500$ & - \\
Piezo stack charge Ch\% (square profile only) & square-boot-ramp & - \\
Oxygen concentration & 0 & $\%($ vol.) \\
\hline
\end{tabular}

Table 3 Fitted experimental correlation coefficients

\begin{tabular}{cl}
\hline Coefficient & Value \\
\hline $\mathrm{k}$ & 4.75 \\
$\mathrm{a}$ & 0.21 \\
$b$ & 0.60 \\
$\mathrm{c}$ & -0.10 \\
$\mathrm{R}^{\wedge} 2$ & 0.984 \\
\hline
\end{tabular}




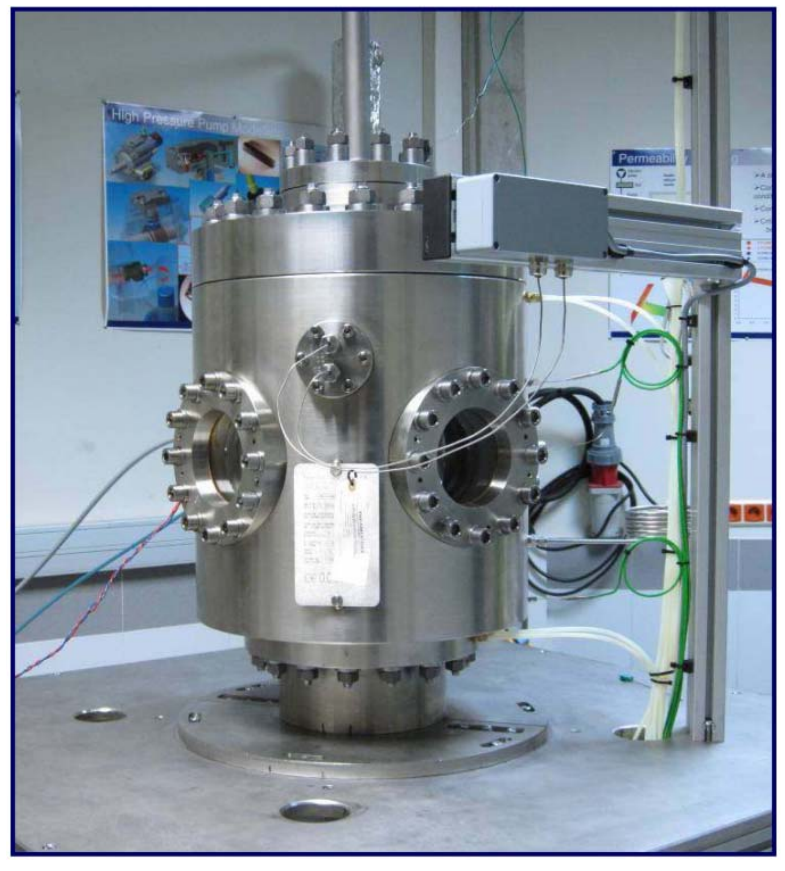

Fig 1

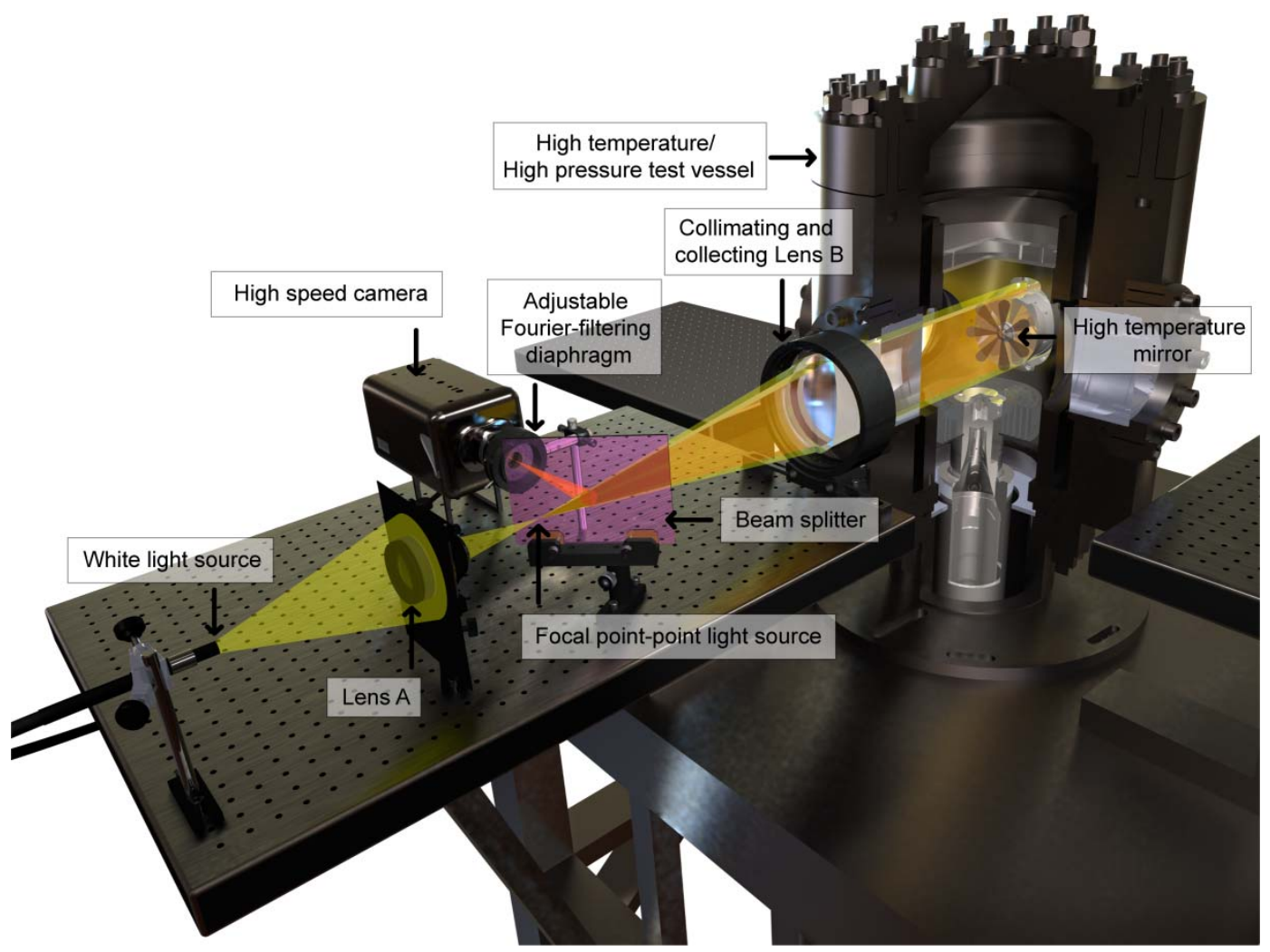

Fig 2

FUEL; Volume: 113; Pages: 257-265; DOI: 10.1016/j.fuel.2013.05.057; NOV 2013 

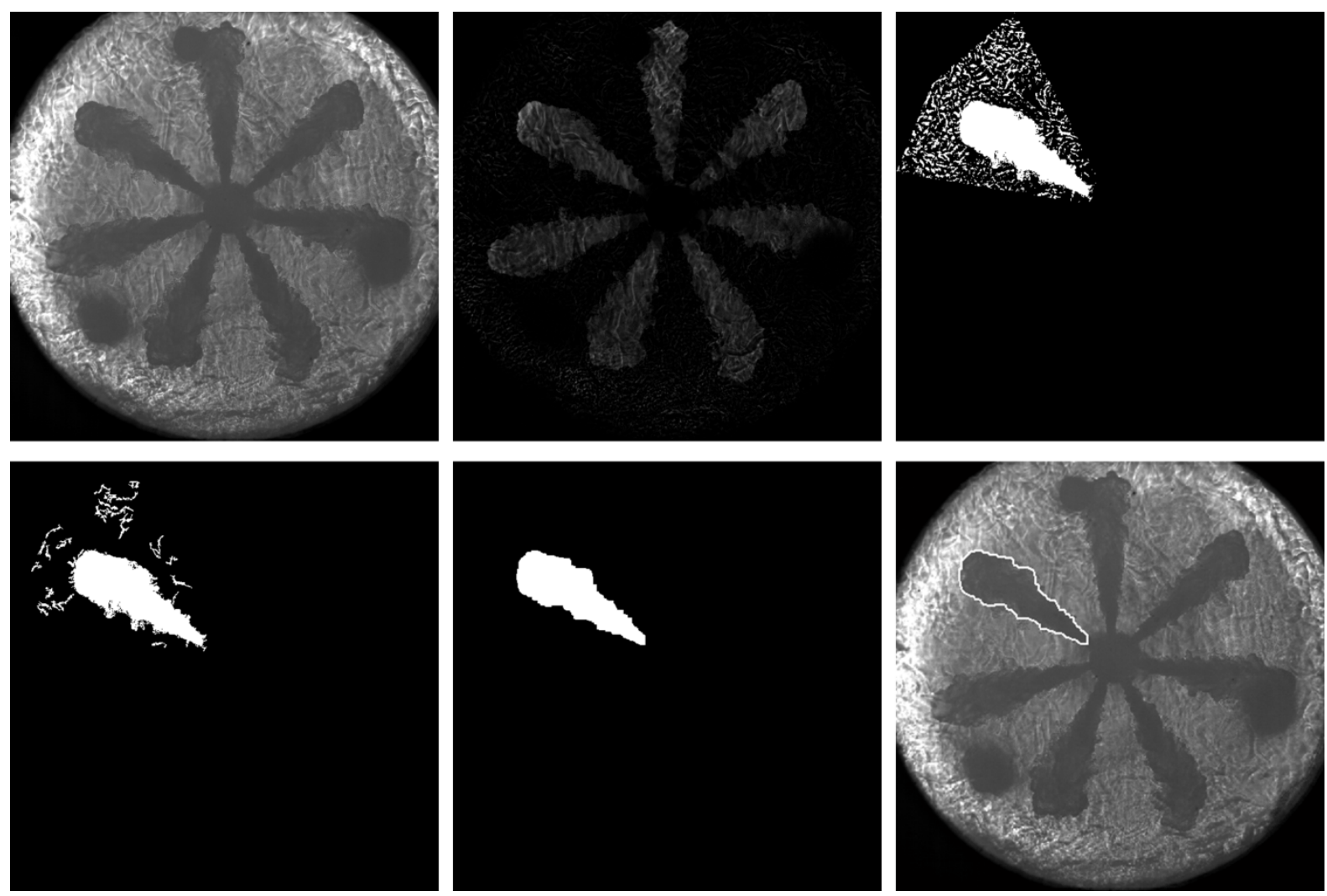

Fig 3
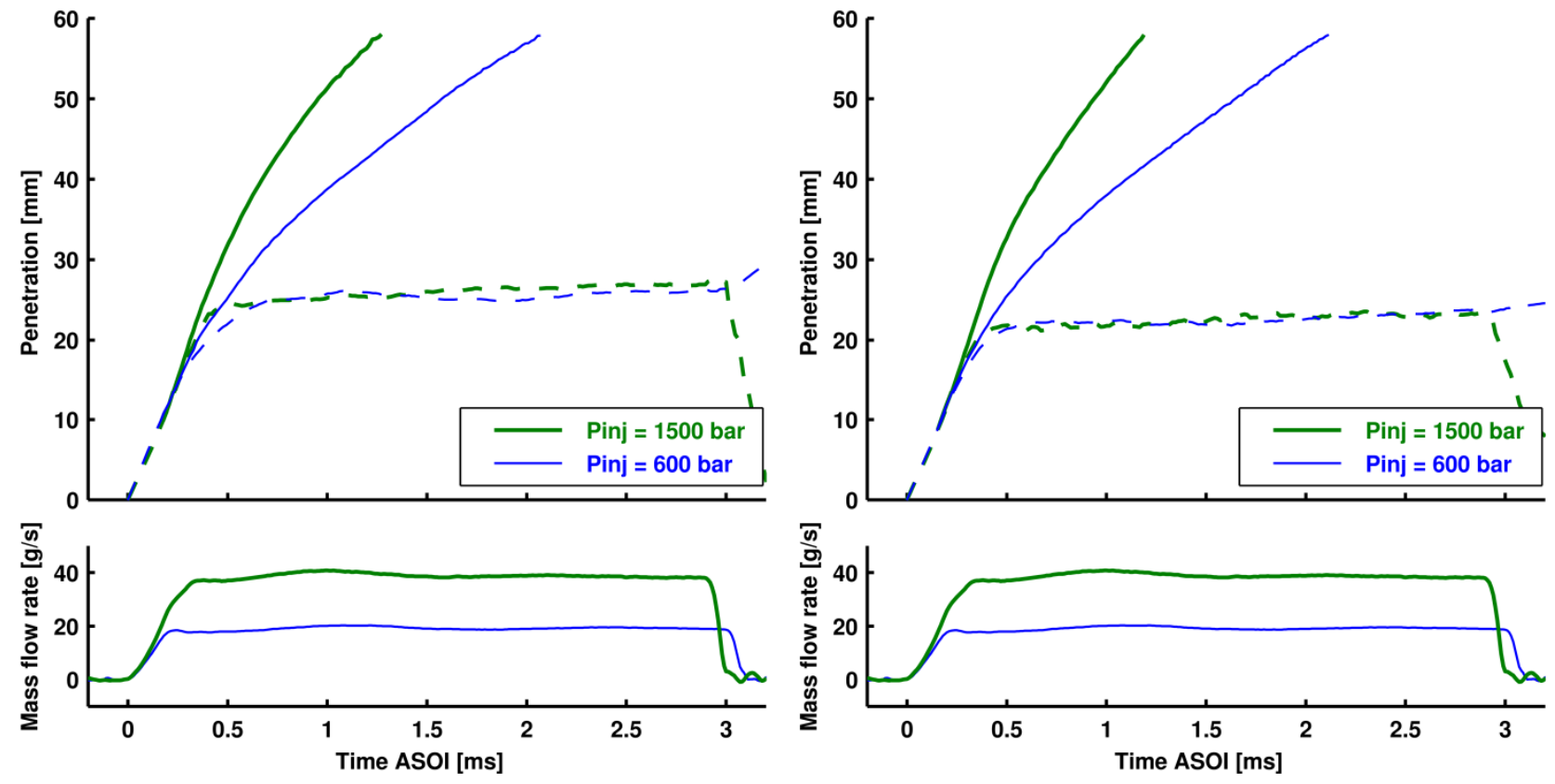

Fig 4 

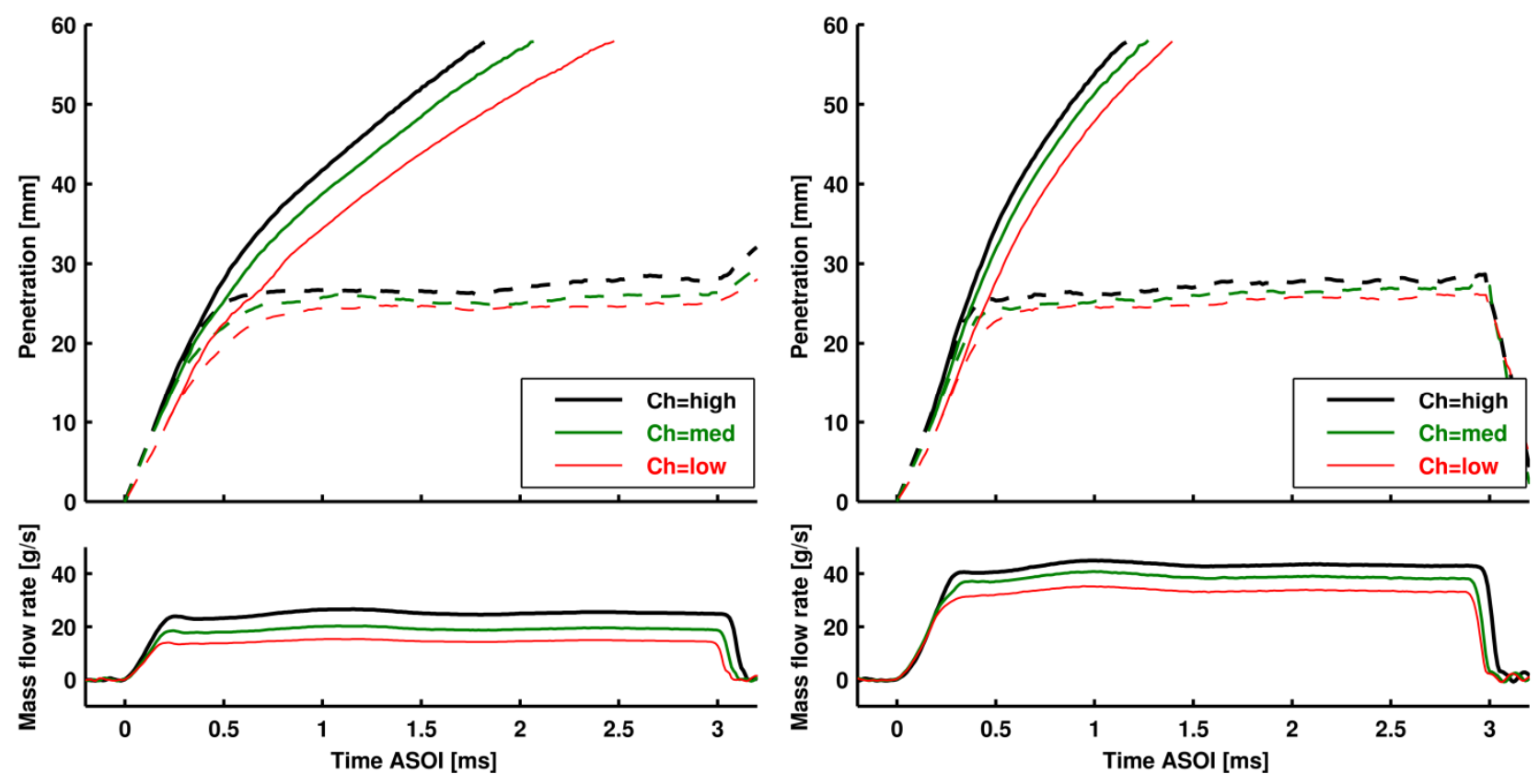

Fig 5
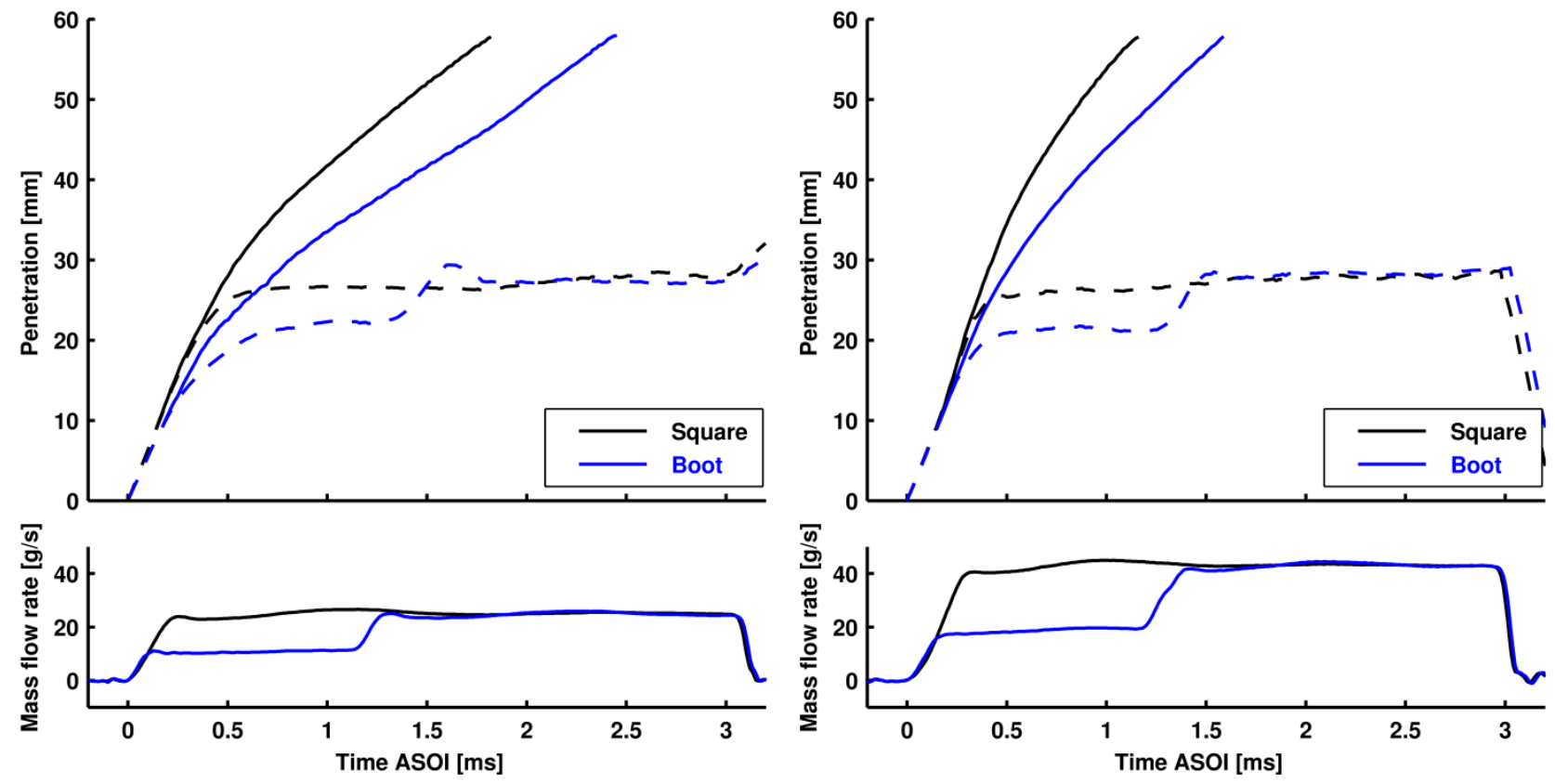

Fig 6 

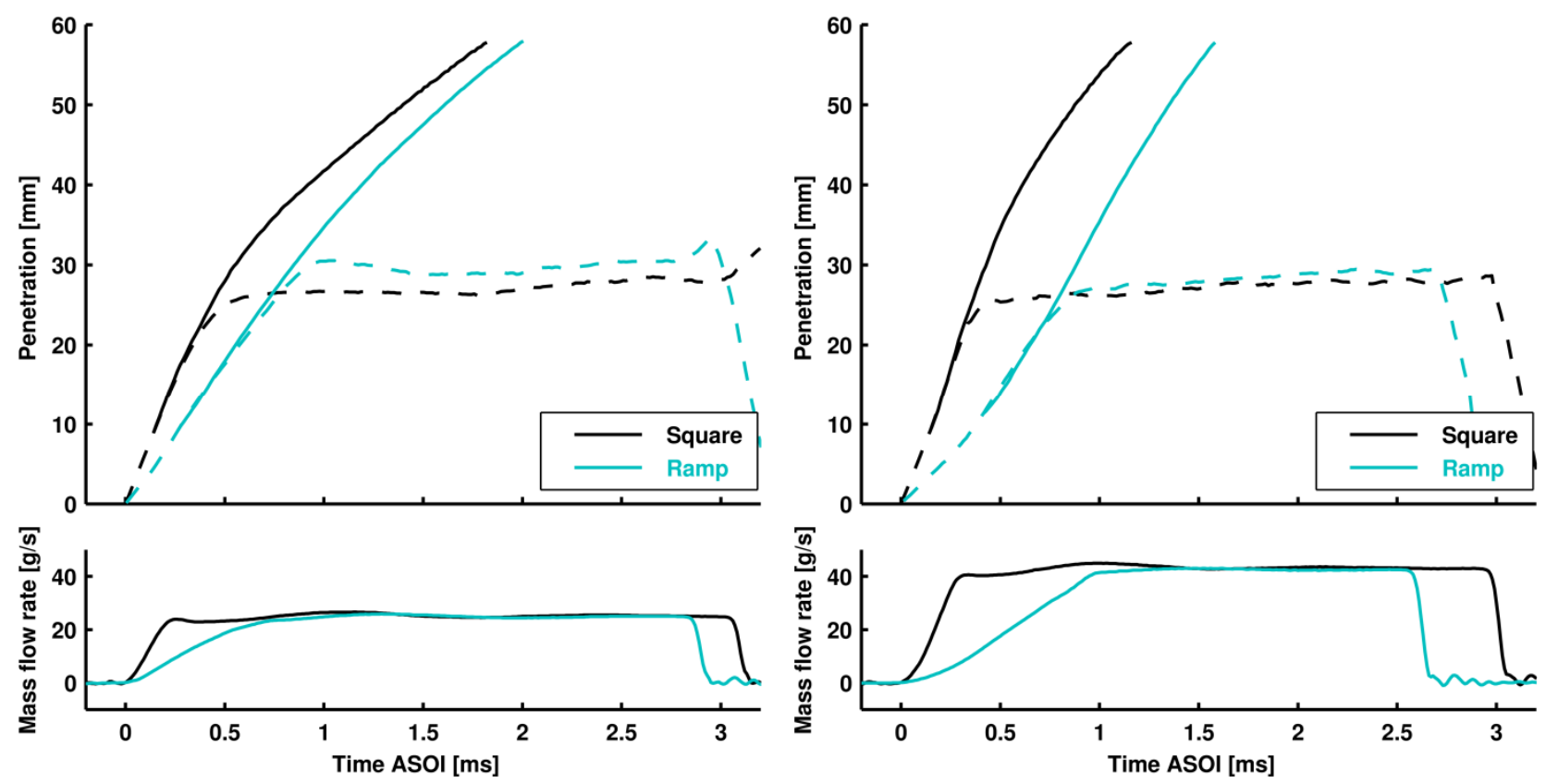

Fig 7
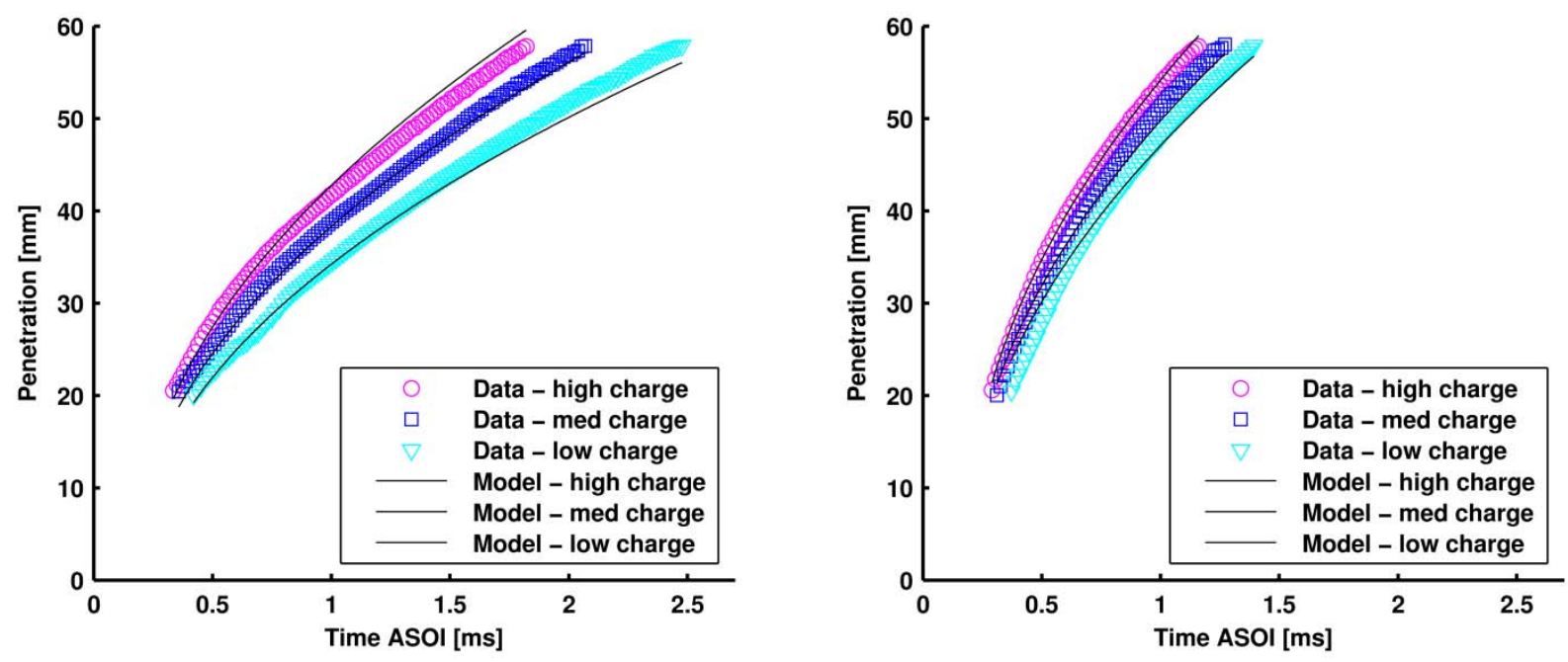

Fig 8 


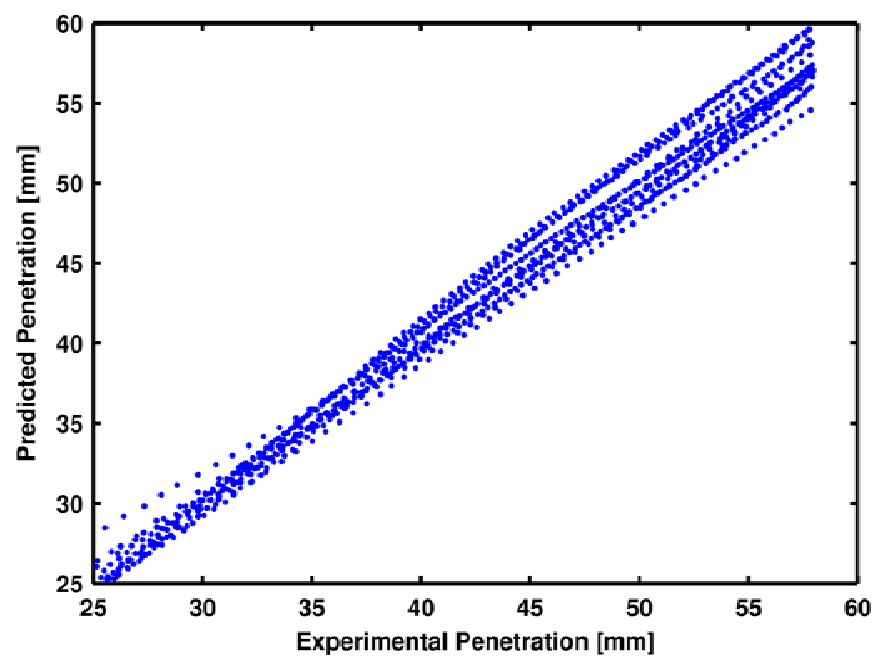

Fig 9

FUEL; Volume: 113; Pages: 257-265; DOI: 10.1016/j.fuel.2013.05.057; NOV 2013 